\title{
The Enduring Potential of Justified Hypernorms
}

\author{
Markus Scholz \\ University of Applied Sciences for Management \& Communication, Vienna
}

\author{
Gastón de los Reyes, Jr.
}

George Washington University

\author{
N. Craig Smith \\ INSEAD
}

\begin{abstract}
The profound influence of Thomas Donaldson and Thomas Dunfee's integrative social contracts theory (ISCT) on the field of business ethics has been challenged by Andreas Scherer and Guido Palazzo's Habermasian approach, which has achieved prominence of late with articles that expressly question the defensibility of ISCT's hypernorms. This article builds on recent efforts by Donaldson and Scherer to bridge their accounts by providing discursive foundations to the hypernorms at the heart of the ISCT framework. Extending prior literature, we propose an ISCT* framework designed to retain ISCT's practical virtue of managerial guidance while answering the demands of Scherer and Palazzo's discursive account. By subscribing to a suitable portfolio of discursively justified hypernorms, we argue, companies unlock the valuable moral guidance of ISCT*, which says to treat these hypernorms as unequivocal outer bounds to the pursuit of business and as a starting point to tailor local norms through discursive stakeholder engagement.
\end{abstract}

KEY WORDS: discourse ethics, human rights, hypernorms, integrative social contracts theory, legitimacy, multi-stakeholder initiatives

Tntegrative social contracts theory's (ISCT) (Donaldson \& Dunfee, 1994, 1999, 2002) long standing as one of the leading approaches to business ethics-in the scholarly literature, as well as in teaching and practice-no doubt stems in part from its formulation as an applied framework, designed to help managers in the field reason thoughtfully and effectively about the ethical conundrums of global business (Gilbert \& Behnam, 2009; van Oosterhout \& Heugens, 2009). It is this virtue of ISCT that motivates us in this article to examine the potential to propose a variation on the framework that accommodates and responds to the Habermas-inspired discursive account of moral legitimacy (DAML) that has also become popular and influential in recent years. The importance of this examination and updating of ISCT is reflected in DAML's increasing influence in the scholarly debate on business ethics. The urgency comes from the fact that DAML calls into question the viability of ISCT's underlying account of moral legitimacy. 
ISCT's distinction as an applied framework is evidenced and enhanced by the diverse areas of practice that scholars have sought to elucidate through the application of the framework, including the marketing of bank products (Reisel \& Sama, 2004), the implementation of global citizenship (Logsdon \& Wood, 2002), intercultural management problems (Bucar, Glas, \& Hisrich, 2003), corporate governance (McCarthy \& Puffer, 2008), gender discrimination (Mayer \& Cava, 1995), sweatshop labor standards (Hartman, Shaw, \& Stevenson, 2003), computer ethics (Conger \& Loch, 2001), and bribery (Dunfee, Smith, \& Ross, 1999).

The capacity of ISCT to speak meaningfully to managers across the domains and cultures of business results from the philosophical foundations that undergird the applied framework theoretically. Building from the "same kind of thought experiment that was used to justify the traditional social contract arguments of Locke, Rousseau, Hobbes, and Rawls" (Donaldson \& Dunfee, 2002: 1855), Thomas Donaldson and Thomas Dunfee's ISCT appeals to hypothetical social contracts as the basis for the moral legitimacy of decision making in global business $(1999,2002,2003)$. Its structured approach to business ethics has been applied by scholars to provide actionable insights in numerous business contexts (see Gilbert \& Behnam, 2009: 218-19). Donaldson and Dunfee offer an account of moral legitimacy based on the plausibility of the (hypothetical) agreement of their contractors. As we explain, the framework either yields an obligation or moral free space. Moral legitimacy is earned by meeting one's obligations.

The focal concept in this article, and arguably the cornerstone of ISCT as a theory, is the "hypernorm," a term coined by Donaldson and Dunfee (1999: 98) to represent "metanorms" that "sit in judgment of lower order norms" (i.e., microsocial norms) (Donaldson, 2017: 138). The most crucial feature of hypernorms as a category in ISCT is that their status as metanorms is deemed to be cross-cultural. This cosmopolitan credential is foundational both to the theory of ISCT - its hypothetical contract account of moral legitimacy_and to the practical guidance ISCT is designed to provide managers through its framework. A key concern of this article is examining and bolstering ISCT's cosmopolitan claim to legitimacy.

Our focus on hypernorms builds on the considerable debate spawned by the concept in the business ethics literature (Boatright, 2000; Douglas, 2000; Dunfee, 2006; Gilbert \& Behnam, 2009; Phillips \& Johnson-Cramer, 2006; Scherer, 2015; Shaw, 2000; van Oosterhout, Heugens, \& Kaptein, 2006; Windsor, 2016). Arguably, the most stinging critique of ISCT has been disseminated by Andreas Scherer and Guido Palazzo in their far-reaching collaboration (Palazzo \& Scherer, 2006; Scherer \& Palazzo, 2007, 2008, 2011; Scherer, Palazzo, \& Baumann, 2006; Scherer, Palazzo, \& Matten, 2014; Scherer, Rasche, Palazzo, \& Spicer, 2016). Their approach has become widely popular in the business ethics and management literatures more generally (as reflected in over four thousand citations for these contributions) and draws inspiration from the thought of Jürgen Habermas and his idea of deliberative democracy (Habermas, 1996, 1998). In contrast to the hypothetical contracts providing ISCT's theoretical roots, the Habermasian camp in business ethics locates the moral legitimacy of managerial decision making in actual discursive engagement among and between companies and the parties impacted 
by business activity. Their distinct conceptual foundations-one premised in hypothetical reasoning and the other in discursive engagement—seem to make each of these leading approaches to business ethics oil to the other's water, and, with few exceptions (Gilbert \& Behnam, 2009), business ethics scholarship that draws upon one does not draw upon the other.

The reason why is plain: the DAML that Scherer and Palazzo advance (see, especially, 2007) is presented by them as necessarily antithetical to ISCT. To embrace a discursive account of moral legitimacy, they assert, is to reject ISCT. And at the heart of that critique-which serves to sharpen Scherer and Palazzo's case for DAML - is the concept and function within ISCT of hypernorms. The fatal flaw with Donaldson and Dunfee's ISCT, argue Scherer and Palazzo (2007: 1102) in what we term the hypernorm challenge, is the justification of hypernorms through a "monological concept of reasoning." The monological reasoning they assert to be faulty — and the challenge to hypernorms - is the hypothetical contract worked out by Donaldson and Dunfee in the form of a thought experiment to reach substantive moral conclusions, i.e., that hypernorms are deserving of their alleged status as cross-cultural metanorms (1994, 1999, 2002, 2003). Scherer and Palazzo argue that neither philosophers nor managers can "justify business obligations or determine ethically sound action by the monological (i.e., non-dialogical) development or application of principles, golden rules, hypernorms, or virtues" (Scherer \& Palazzo, 2007: 1103). Consequently, they rule out any a priori justification of hypernorms (Scherer \& Palazzo, 2007: 1102; cf. 1103, 1108), concluding that "because of its monological concept of reasoning" (2007: 1102), ISCT cannot provide legitimate moral guidance to managers (cf. van Oosterhout et al., 2006).

The gulf between ISCT and the Habermasian, discursive approach to business ethics - and the potential for reconciliation and mutual alignment—was recently broached by Scherer and Donaldson themselves, in connection with this journal's special issue (vol. 25, no. 4, 2015) titled "Normative Business Ethics in a Global Economy: New Directions on Donaldsonian Themes." Scherer's (2015) contribution to the festschrift, "Can hypernorms be justified?," restates the concern with monological reasoning ("Donaldson and Dunfee did not sufficiently explore the significance of the procedure by which (hyper-)norms can be identified and justified") but then immediately pivots towards reconciliation: "Therefore, I suggest building on the insights of discourse ethics and analyzing the argumentative process by which the validity of norms, even the validity of hypernorms, can be checked" (2015: 507, emphasis added). In reply, Donaldson acknowledges the force of the hypernorm challenge: "Tom Dunfee and I neglected discursive requirements [and] said little about stakeholder communication and participation in the process of public reasoning" (2017: 137). More importantly, Donaldson then commences to address the limitation: "The best procedures for isolating principles in business should reflect something like an ideal speech situation and include employee voice, stakeholder dialogue, discursive democracy, and public conversation" (2017: 137).

We believe the dialogue between Scherer and Donaldson is fruitful and sets the stage for probing, and potentially, reconciling the inconsistency that Scherer and Palazzo assert exists between DAML and ISCT. Instead of directing energies to 
adjudicating the normative force of the case for DAML in business ethics as others have done (see Hussain \& Moriarty, 2016) or the case for ISCT on its own terms (see Scherer, 2015, and many others), we set our sights on formulating a revised version of ISCT_-ISCT*_-designed to withstand the force of the critique from DAML so as to build upon its intercontextual practicability.

Thus, our purpose in this article is to lay groundwork for an ISCT* that is useful to managers yet does not depend upon a monological concept of reasoning for justification.

We proceed as follows. In section 1, we review ISCT's hypothetical contract foundations and the function of hypernorms in its managerial framework for making morally legitimate business decisions in a globalized business world. In section 2, we summarize Scherer and Palazzo's critique of ISCT as reflected in the hypernorm challenge presented by DAML. To pursue the constructive project, we take direction from Scherer (2015) and Donaldson's (2017) apparent openness to the potential for an account of hypernorms that includes discursive input legitimacy conditions (Mena \& Palazzo, 2012). More concretely, in section 3, we draw from Gilbert and Behnam's (2009) significant effort to build upon and respond to concerns raised by earlier critiques of ISCT by proposing to define processual requirements that serve as necessary conditions for the moral legitimacy of hypernorms. We view Gilbert and Behnam's proposal as giving rise to the concept of "justified hypernorms," i.e., hypernorms that have garnered justification (moral legitimation under DAML) via their discursive genesis.

In section 4, we critically assess the limitations of Gilbert and Behnam's proposal given ISCT's requirements of universal scope and bindingness for hypernorms. This examination leads us to ISCT*, an amended version of the framework that looks not to the hypernorms characterized by Donaldson and Dunfee, but to the portfolio of (arguably) justified hypernorms to which a manager's company has actually subscribed. In section 5, we put ISCT* to the test and find that ISCT*, when coupled with a suitable hypernorm portfolio, sets an outer bound (or negative sanction) on business conduct and norms (e.g., defining human rights commitments of the company) that is defensible under DAML. In section 6, we argue that ISCT* faces a fundamental limitation not acknowledged by Gilbert and Behnam: justified hypernorms cannot, under the demands of DAML, endorse the legitimacy of conduct or lower order norms, one of the basic functions and promises of Donaldson and Dunfee's hypernorms. Nevertheless, we go on to argue that hypernorm portfolios can play a defensible and valuable role as a starting point for managers to engage discursively with stakeholders to tailor norms to local contexts. In section 7, we summarize key questions companies have to ask to develop suitable hypernorm portfolios to get the most value from ISCT* ${ }^{*}$. In concluding, we summarize the findings and limitations of our analysis and sketch implications for managerial practice and further research.

\section{ISCT AS A GUIDE TO THE MORALLY LEGITIMATE NORMS THAT BIND MANAGERS}

Fundamentally, ISCT provides a "norm-taking framework," assisting the manager in the exercise of picking and choosing from among externally presented microsocial norms those that are deemed legitimate and binding (de los Reyes, Scholz, \& Smith, 2017). 
This positions the framework to answer norm-taking questions: "By whose standards should business be judged?" and "Do corporations have any obligation to protect the human rights of those affected by their decisions?" (Donaldson \& Dunfee, 1999: vii). It is its pioneering effort to help managers distinguish legitimate and binding norms from norms that do not bind, for want of legitimacy, that gives ISCT its strength and deserved recognition as a major contribution to business ethics thought (see Boatright, 2000; Brenkert, 2009; Gilbert \& Behnam, 2009; Stark, 2015; van Oosterhout et al., 2006).

The theoretical motivation for ISCT comes from the conception of a "macrosocial contract" that encompasses the global community of people doing business (1999: 37). What do we share as people pursuing our economic interests? Donaldson and Dunfee anchor their account around two core ideas:

(1) People "bring with them the underlying sense of right and wrong with which they have grown up. They bring with them these settled understandings of deep moral values, which we will call "hypernorms"” (Donaldson \& Dunfee, 1999: 27). ${ }^{1}$

(2) People want to have the liberty to join different economic communities, meaning that "ethical norms must be contoured to the rules of the specific economic practices and the notions of fairness of the participants" (Donaldson \& Dunfee, 1999: 32).

The thought experiment involved in working out the terms of the macrosocial contract entered into, based on these commitments, has several important features. It is intended to be universal, an imagined contractual engagement by and among "the citizens of all nations" (thus, universal in its hypothetical macrocontractual genesis) that binds all (thus, universal in its binding reach) in respect of the full spectrum of business activities around the globe (thus, universal in scope; viz., a metanorm) (Donaldson \& Dunfee, 1999: 218).

The ISCT framework that Donaldson and Dunfee develop as the embodiment of the macrosocial contract is designed to give practical guidance that is responsive to both its anchoring ideas. On the one hand, Donaldson and Dunfee "deny that one can know in advance what the correct rules of business ethics are for a specific system without having detailed information about the system and its participants" (1999: 32). That is why the imagined macrosocial contractors "must rely—at least partially—upon community-specific microsocial contracts for establishing contextually appropriate rules of economic ethics" (Donaldson \& Dunfee, 1999: 37). This commitment to liberty in joining economic communities that are to varying degrees self-constituting leads Donaldson and Dunfee to conclude that the contractors will, first, agree that "local economic communities possess moral free space in which they may generate ethical norms for their members through microsocial contracts" (1999: 41) and "as a means of enabling the satisfaction of personal precepts and economic efficiency" (1999: 38).

On the other hand, the anchoring of the macrosocial contract around "settled understandings of deep moral values" provides the second basic term of the ISCT framework: the moral free space to do business legitimately through microsocial contracts (or otherwise) is bounded and subject to hypernorms that apply everywhere as the lowest common denominator standard-bearer of moral legitimacy. Hypernorms set a moral 
minimum on acceptable conduct and, by implication, on the legitimacy of microsocial norms (Donaldson \& Dunfee, 1999: 44).

To provide a tangible managerial framework, ISCT goes beyond a prioritization of commitments to provide the desired norm-taking guidance. For microsocial norms, the question, as framed by Donaldson and Dunfee, is determining which among the sea of local norms (i.e., microsocial norms) that confronts managers (see Bicchieri, 2016) are authentic, meaning that they reflect the commitments of a microsocial community and, therefore, qualify as potentially binding. Under Donaldson and Dunfee's hypothetical contracts conception, the touchstone is hypothetical consent. The first part of consent is the brute fact that a majority of the participants in the economic community heed the norm (see Donaldson and Dunfee, 1994: 39). That alone is too lenient a criterion for the macrosocial contractors, according to Donaldson and Dunfee. There is the risk that popular norms could exist without warranting an inference of authenticity. A community's governance could be dictatorial and impose norms that are followed only under oppression. Countering this risk, Donaldson and Dunfee reason that the macrosocial contractors would require that as a condition of authenticity (and for norms to be able to bind), members of communities must enjoy a right to voice. And to bind even those members of a community who disapprove of the norms, Donaldson and Dunfee also hold that to be authentic norms must emerge from communities that allow members the right of exit. Leaving aside complications arising from conflicts among microsocial norms (Donaldson \& Dunfee, 1999: 175-212), the satisfaction of these two conditions — rights to (1) voice and (2) exit—render prevalent norms authentic and, therefore, putatively binding.

How are managers to identify the hypernorms that set the outer bounds of global business? Donaldson and Dunfee provide heuristics for inquiring after hypernorms, rather than a settled list, opening them up to criticism from many for the vagueness of their answer. For example: "We would expect [hypernorms] to be reflected in a convergence of religious, philosophical, and cultural beliefs, and, indeed, such convergence is a handy clue to use in attempting to specify hypernorms" (1994: 265). In their book, they write that there should at least be "a reasonable hope that we should discern such a convergence" (1999: 44).

In sum, authentic microsocial norms are morally legitimate and binding if, and only if, they do not conflict with hypernorms. The biconditional "if and only if" means, first, that authentic norms are morally legitimate and binding only if they are compatible with hypernorms. Crossing the bound of hypernorms-i.e., following a microsocial norm that clashes with hypernorms - exposes managerial action to moral illegitimacy. The second implication of the biconditional is that authentic norms are morally legitimate if compatible with hypernorms. We return to this affirmative endorsement of moral legitimacy in section 6.

\section{SCHERER AND PALAZZO'S DAML AND CRITIQUE OF ISCT-THE HYPERNORM CHALLENGE}

In their highly influential 2007 article, and as further developed in a series of other well received articles (e.g., Palazzo \& Scherer, 2006; Scherer \& Palazzo, 2007, 
2008, 2011), Scherer and Palazzo look to Habermasian theory to provide a different account of moral legitimacy in business ethics. Given recent theorizing (e.g., Hussain \& Moriarty, 2016), it is important to emphasize the extent to which Scherer and Palazzo understand there to be a meaningful divide between the early Habermas (or Habermas1) (Habermas, 1984, 1985, 1990, 1993) and the later Habermas (or Habermas2) (e.g., 1996). Habermas1 emphasizes ideal discourse defined to satisfy a series of "conditions includ[ing] freedom of access, participation with equal rights, truthfulness of the participants, and 'absence of coercion"” (Scherer \& Palazzo, 2007: 1104). On this view, the moral legitimacy of any norm that emerges from ideal discourse stems, not in a purported correspondence with objective moral truth, but in the "consensus of all experts and affected people" (2007: 1105). Habermas2, in contrast, emphasizes the concept of deliberative democracy. Scherer and Palazzo argue that the deliberative engagement of corporations with multiple stakeholders in multi-stakeholder initiatives (MSIs) serves to legitimize corporations in their role as political actors.

Scherer and Palazzo choose to build from deliberative democracy (Habermas2), not because they doubt the capacity of ideal discourse to ground moral legitimacy (see Hussain \& Moriarty, 2016), but rather because ideal discourse "provid[es] a more utopian than realistic orientation for corporate behavior" (Scherer \& Palazzo, 2007: 1105). The key difference between the early and the later Habermas on this view is the willingness under the latter to relax the strictures of the ideal speech situation and to allow, and instead call for, "small steps of constant improvement and transformation of real democratic processes and institutions" (2007: 1107). Seen thus, consensus is not absolutely essential so long as the discursive process yields a rational basis for disagreeing about the moral remainder (see Hursthouse, 1995) that keeps the conversation going.

In characterizing DAML, Scherer and Palazzo aim to set forth a conception of moral legitimacy that can be applied to business, as we find it today operating across the "post-national constellation" (Scherer \& Palazzo, 2008). The hallmark of their DAML is anchoring moral legitimacy on the processual inputs to social norm-making processes. Specifically, "the legitimacy of a political decision rests on the discursive quality of the decision-making process" (Scherer \& Palazzo, 2007: 1107). It is the requirement to practice deliberative democracy, therefore, that we take to be definitive of DAML's conception of corporate legitimacy. Scherer and Palazzo position moral legitimacy not as a past tense, check-the-box compliance model (i.e., the company enjoys moral legitimacy because managers fulfilled their obligations), but as a present tense and dynamic discourse-based conception: "[f]or a corporation to deal with changing societal demands in a reasonable way, it must replace implicit compliance with assumed societal norms and expectations with an explicit participation in public processes of political will formation" (Scherer \& Palazzo, 2007: 1108; cf. Scherer \& Palazzo, 2011). We capture this way of distinguishing ISCT's conception of moral legitimacy from DAML's by referring to their respective modalities (see Table 1).

The underlying oil-and-water mismatch between Donaldson and Dunfee's conception of hypernorms (D\&D's hypernorms) and DAML is therefore simply stated: "The difficulties lie in the presupposition that the members of a particular community 
Table 1: ISCT and DAML_Logic, Mechanism, and Modality

\begin{tabular}{|c|c|c|c|}
\hline & ISCT & DAML & ISCT* \\
\hline Logic & Hypothetical contract & Deliberative democracy & $\begin{array}{l}\text { Deliberative democracy / public } \\
\text { (quasi-contractual) hypernorm } \\
\text { commitments }\end{array}$ \\
\hline Mechanism & $\begin{array}{l}\text { Touchstones include } \\
\text { compatibility with } \\
\text { hypernorms and authenticity } \\
\text { of microsocial norms }\end{array}$ & $\begin{array}{l}\text { Norm-making via } \\
\text { ongoing multi- } \\
\text { stakeholder } \\
\text { initiatives }\end{array}$ & $\begin{array}{l}\text { Fidelity to public contractual } \\
\text { commitments and ongoing } \\
\text { openness to norm-making via } \\
\text { multi-stakeholder initiatives }\end{array}$ \\
\hline Modality & $\begin{array}{l}\text { Static, "check the box safe } \\
\text { harbor," property-like }\end{array}$ & $\begin{array}{l}\text { Dynamic, an activity } \\
\text { of open engagement, } \\
\text { process-based }\end{array}$ & $\begin{array}{l}\text { Dynamic, outer bounds guidance, } \\
\text { and poised to engage } \\
\text { stakeholders discursively }\end{array}$ \\
\hline
\end{tabular}

have agreed to the terms of a social contract" (Scherer \& Palazzo, 2007: 1102; see Dworkin, 1973). As a matter of the framework's infrastructural logic, the plausibility of ISCT for macrosocial contractors depends upon the existence of identifiable and universally agreeable metanorms that transcend cultural and national boundaries (i.e., D\&D's hypernorms). Otherwise, why would macrosocial contractors choose D\&D's hypernorms to serve as the legitimacy-bestowing touchstones that draw a universal line dividing morally binding and morally prohibited microsocial norms (outside of which managers enjoy moral free space)? To undercut D\&D's hypernorms' claim to moral legitimacy, therefore, is also to undercut the moral legitimacy of ISCT itself. And this is what Scherer and Palazzo purport to do. To them, D\&D's hypernorms, based as they are on the supposed existence of "convergen[t] religious, cultural, and philosophical beliefs" (Donaldson \& Dunfee, 1999: 59), provide at best 'the 'hypothesis,' 'assumption,' and 'presumption' of the theorist" (2007: 1102, emphasis in the original). Scherer and Palazzo elaborate:

Any metanorm must be considered as a suggestion of the theorist, and one must wait to see whether these metanorms can be considered justified - that is, that they are acceptable to all concerned. This, however, can be tested only in a discursive process with the people involved and cannot be verified in advance on the theorist's desk (2007: 1102).

This is exactly where the wedge between DAML and Donaldson and Dunfee's ISCT is driven: ISCT's macrosocial contractors were "unwilling to go so far as to mandate the existence of such a process [of stakeholder discourse] as a condition" for moral legitimacy, whether in generating microsocial norms or discerning valid hypernorms (2003: 119).

So long as one aspires to answer the demands of DAML, D\&D's hypernorms do not have the conceptualization required for justification-the people bound by these norms never actually jointly endorsed an authoritative rendering of the lines drawnand this destabilizes ISCT's infrastructure. If D\&D's hypernorms lack the justification needed under DAML, that means they cannot serve the function ISCT assigns them: distinguishing legitimate and binding authentic norms from microsocial norms that are morally prohibited, whether or not authentic. It is along this fault line that Donaldson (2017: 137-38) acknowledges the potential to bolster ISCT's legitimacy. 


\section{DISCURSIVELY JUSTIFIED HYPERNORMS—AN ATTEMPT TO OVERCOME THE HYPERNORM CHALLENGE}

We begin our constructive exercise with Gilbert and Behnam's (2009) intriguing and potentially fruitful proposal to address the hypernorm challenge and avoid the limitations of monological reasoning, anticipating the recent suggestions offered by Scherer (2015) and Donaldson (2017) who posit that hypernorms can be justified via Habermasian discursive processes. In contrast with other scholars who have suggested abandoning ISCT altogether (e.g., van Oosterhout et al., 2006), Gilbert and Behnam seek, precisely as we do, to address the hypernorm challenge so as to preserve and build upon the "potential of ISCT in producing action guiding norms for managers" (2009: 216).

Gilbert and Behnam's strategy for realizing this promise is to extend the category of procedural hypernorms - which, in Donaldson and Dunfee's taxonomy of hypernorms, provide the source of the exit and voice requirements for the authenticity of microsocial norms (Donaldson \& Dunfee, 1999: 54)—to reach hypernorms. In doing so, they appeal to principles of input legitimacy derived from Habermas's discourse ethics (see, generally, Mena \& Palazzo, 2012), paying special attention, as do Scherer and Palazzo, to the concept of deliberative democracy (Habermas, 1996, 1998, 2001, 2006; cf. Gilbert \& Behnam, 2009: 216, 225). The procedural legitimacy of hypernorms, they propose, comes from representative multi-stakeholder forums that constitute argument-based and, to the extent possible, power-free discourse where the relevant issues can be discussed. Habermas (1996) recognizes that these conditions for ideal speech situations are idealistic; i.e., difficult, if not impossible, to realize in real-life discourse. Nevertheless, in Gilbert and Behnam's reading of DAML, "this does not in principle preclude the possibility that these assumptions can usefully inform the conduct of dialogues" (2009: 222-23).

The basic requirement for Gilbert and Behnam, therefore, is the premise that "those being affected by a norm must be able to participate in a real argumentation regarding its validity" (2009: 216). ${ }^{2}$ We refer to this as the "input legitimacy condition," where "input legitimacy" refers to a norm's "rule credibility" by virtue of its processual history — who talked to whom, when, where, and how (Mena \& Palazzo, 2012). Their insight at the juncture of ISCT and the discourse tradition is thus to posit that real-world discursive processes can (and should), in theory, provide a justification of hypernorms consistent with DAML (Donaldson \& Dunfee, 2009: 216). Gilbert and Behnam's suggestion can be summarized as follows: First, in keeping with the hypernorm challenge and earlier critical commentary, they identify the major shortcoming of ISCT to be its monological account of hypernorms. Second, they propose that if hypernorms are derived from Habermasian discursive processes and meet the input legitimacy condition, they may be justified. Third, they seek to maintain the mechanism of ISCT (Table 1), namely its decision rule binding managers to live up to the requirements of (1) hypernorms in everything they do, and (2) authentic microsocial norms insofar as they are consistent with hypernorms - the key difference for Gilbert and Behnam being that the hypernorms in question are justified hypernorms. 
For many reasons already indicated, not least Scherer's (2015) and Donaldson's (2017) endorsement of the strategy, we agree that Gilbert and Behnam have identified in hypernorms the proper site for a corrective intervention into ISCT, given the challenge posed by DAML. However, the project that Gilbert and Behnam started is far from complete. We continue next with a critical assessment of their proposal insomuch as it assumes that justified hypernorms can readily swap into ISCT without structural repercussions. This is simply not the case. Thus, we now analyze why and propose important conceptual adjustments that are required to achieve a workable ISCT*.

\section{ARRIVING AT JUSTIFIED HYPERNORMS WITH UNIVERSAL SCOPE AND DEFENSIBLE BINDINGNESS}

To test the robustness of Gilbert and Behnam's proposal to justify hypernorms discursively in this and the next section (5), our method is to check it against the account of ISCT's distinctive features as presented above. In this section, we focus on the two universality conditions of D\&D's hypernorms: (1) universality in scope (applies to all kinds of business activities), and (2) universal bindingness (applies to all business actors). Our objective and contribution in this section is to evaluate and extend, as necessary, Gilbert and Behnam's proposal on these dimensions to arrive at an ISCT* we can trial. We critically assess universality of scope in section 4.1 and make an amendment that leads us to introduce ISO 26000 as a candidate portfolio of arguably justified hypernorms in 4.2. In 4.3, we examine the question of universal bindingness, which requires a further adjustment to the operationalization of the framework.

\subsection{The Scope of Justified Hypernorms}

To be a metanorm means that hypernorms have the property of universality in scope-enjoying priority as higher order norms in all contexts: "to evaluate lower-order norms" as "norms by which all others must be judged" (Donaldson \& Dunfee, 1999: 44; Donaldson, 2017). Hypernorms are metanorms whose form grants them universal scope; i.e., they are "universal principles" (1999: 49) that speak and apply to human activity and needs globally and across business contexts generally.

Gilbert and Behnam do not identify this dimension of universality in D\&D's hypernorms, and we take the opportunity to stress its importance by showing why the exemplar they use to model discursively justified hypernorms, the Forest Stewardship Council (FSC) (2009: 225), fails to meet the requisite criterion.

What the FSC aptly models — and Gilbert and Behnam rightly highlight to elucidate the nature of justified hypernorms - is that the FSC provides a forum "where corporations and NGOs meet and develop sets of principles and criteria for sustainable forest management" (Gilbert \& Behnam, 2009: 225; cf. Forest Stewardship Council, 2014; Scherer and Palazzo, 2007). However, the FSC has not yielded cosmopolitan, all-purpose principles for business, but rather industry-specific norms that are not at all universal in scope. The FSC's area of influence is limited to a specific industry (forestry). Take Principle 3 of the FSC as an example: "The Organization shall identify and uphold indigenous peoples' legal and customary rights of ownership, use and 
management of land, territories and resources affected by management activities" (FSC 2014, Principle 3). Although this principle might, to some extent, be functionally transferable to other industries (e.g., Brazil nut planters), it was intentionally designed by, and speaks to, the forestry industry only. Only forest industry participants subscribed to the process that yielded its norms.

This undercuts the standing of FSC norms as metanorms since few of its principles speak to issues relevant across the universe of business practice. FSC Principle 3, for example, provides no guidance to technology companies involved in capturing and selling user data. In contrast, "human rights" by their intrinsic universalitythey apply to all humans in any context—have practical relevance for the business practices of companies in the tech and in every other sector.

This is not simply an arguably technical problem of form under ISCT (viz. metanorm), but goes to the heart of DAML's requirements. Do the FSC principles actually enjoy the input legitimacy required of a justified hypernorm? Gilbert and Behnam look to FSC as a model because they assume its norms were developed with a legitimate array of voices from the forestry industry and those impacted by it. It is not clear, however, that this assumption holds if its principles are put to the service of metanorms trumping norms of other industries, such as high tech and higher education.

We address this oversight by stipulating expressly that a putative justified hypernorm should display universality of scope in its form and express reach-and still arguably meet the input legitimacy condition.

In our effort to construct an ISCT*, we face, at the threshold, the empirical question of whether there are examples of portfolios (sets) of universal principles that arguably do, or could, meet the input legitimacy condition. We see no a priori reason to assume or conclude that the category of justified hypernorms that meets these requirements is a null set. To the contrary, in order to advance a plausible ISCT* we continue in the next section by arguing that ISO 26000 presents a strong case for a portfolio of arguably justified hypernorms that fit the scope requirement. ${ }^{3}$

\subsection{ISO 26000 as a Portfolio of Arguably Justified Hypernorms}

ISO 26000 was launched in 2010 after five years of negotiations between scores of stakeholders that included representatives from government, NGOs, industry, consumer groups, and labor organizations around the globe (ISO, 2017a). This multi-stakeholder initiative was developed against the background of ongoing globalization processes that are characterized, on the one hand, by nation states facing challenges to their regulatory power (Scherer \& Palazzo, 2008) and, on the other, by corporations and other institutional actors increasing their reach and influence. ISO 26000, initiated by the International Organization for Standardization (ISO) to address the social responsibility of organizations generally, was developed between 2005 and 2010 in an elaborate multi-stakeholder process that included meetings in eight working group plenary sessions, with additional committee meetings and supplemental digital consultations (ISO, 2010; Hahn \& Weidtmann, 2016). The guidelines adopted in 2010, ISO 26000 (ISO, 2010), are meant to encourage "every organization ... to become more socially responsible by using this International Standard," aiming to offer "ways to integrate socially responsible 
behavior into the organization." It provides voluntary guidance on the scope of social responsibility, with best-practice examples and various strategies for the implementation of responsible management practices in various kinds of organizations (Hahn \& Weidtmann, 2016: 91; cf. Hahn, 2012a, 2012b). ISO, for instance, contains a concrete declaration of commitment to universal human rights (ISO, 2010: §6.3: 23) such as those set forth in the International Bill of Human Rights, and asks companies to comply with these rights (ISO, 2010: §4.8: 13; §6.3: 23) and provides concrete guidance on how to deal with third parties, e.g., "an organization should not provide goods or services to an entity that uses them to carry out human rights abuses" (ISO, 2010: $\$ 4.8 ; \S 6.3$ ). ISO 26000 is recognized in this literature as a strong representative of a multi-stakeholder discursive approach designed to set forth global guidelines for each and every company globally willing to sign up or otherwise adhere, without regard, to industry (Hahn \& Weidtmann, 2016).

Relative to the limitations we identified in respect of the FSC principles, the scope of ISO 26000 is clearly beyond the confines of any one specific industry: "[it] provides guidance to all types of organizations, regardless of their size or location" (ISO, 2017b). As such, the scope of ISO 26000 norms can be applied by members of all industries to the range of their activities. Thus, the problem of scope we identified above could, in theory, be solved by industry neutral and universalist approaches such as ISO 26000; provided they make a case for meeting Habermasian standards of multi-stakeholder discourse (i.e., meet the input legitimacy condition).

The roots of ISO 26000 are promising for its status under DAML. The process giving rise to these universalist metanorms involved discourse that targeted business generally and globally with stakeholders across industries, countries, and interest groups (input legitimacy). Scholars have also observed that the ISO took care to reduce bargaining power asymmetries among stakeholder-participants negotiating the norms (Hahn, 2012a; 2012b). Adopting a Habermasian perspective consistent with DAML, Hahn and Weidtmann (2016) conclude that the process giving rise to ISO 26000 "is characterized by a relatively high level of normative legitimacy stemming in particular from its multi-organizational, multi-stakeholder approach involving experts from different regions, organizational settings, and interest groups" (2016: 117). And Castka and Balzarova (2008: 303) argue that the extensive multistakeholder discourse leading to the development of ISO 26000 has resulted in "the most legitimate CSR 'document' currently available."

As such, ISO 26000 might qualify as a portfolio of justified hypernorms that display universality of scope and make a strong case for legitimacy with their correspondingly universal roots. Therefore, we refer to the ISO 26000 as an arguably justified portfolio of hypernorms.

\subsection{The Question of Universal Binding Reach}

With our proposed definitional amendment to preserve the logic of ISCT (justified hypernorms must have universal scope and correspondingly universal roots), we now proceed to examine the other dimension of universality: universally binding reach. We also retain our example of an arguably justified portfolio of hypernorms (ISO 26000) to give the theory traction. We will demonstrate that justified hypernorms-even 
if they display universal scope and correspondingly universal roots-cannot offer the universal bindingness promised under ISCT in a way that satisfies DAML. The lack of universal bindingness will not be fatal for an ISCT*, but it will require a substantial modification of the framework's operationalization.

Central to Donaldson and Dunfee's objective with the ISCT thought experiment is grounding inferences about being bound to comply with "core human values" (Donaldson, 1996), anywhere, anytime, in any industry. Everyone should respect human rights - whatever they are - and that should be a moral minimum everywhere. Does ISO 26000 (or any other conceivable portfolio of arguably justified hypernorms) enjoy such binding reach? It seems to us obvious that managers can, at least in some cases, reasonably question whether the specific social responsibility agreements drafted into the ISO guidelines are binding upon them, absent the express consent of the regulated party (typically their employer). And looking ahead to the perspective of stakeholders and the question we tackle in section 6, we can easily imagine stakeholder groups questioning whether the requirements in ISO 26000 are stringent enough in this or that specific context.

On what grounds, then, would the managers of companies that had nothing to do with ISO 26000 be instructed by a moral framework to follow its requirements? Note that ISO 26000 is broad enough to get into controversial areas such as responsible political involvement and sustainable resource use. Absent a theory of hypothetical consent, there is no self-evident basis to hold a company that neither participated in the development process for ISO 26000, nor has since signed up for it (i.e., consented), morally illegitimate for a failure to fulfill its expressly specified norms - notwithstanding ISO 26000's satisfaction of the input legitimacy condition. ISCT would reach the same conclusion if treating ISO 26000 as a microsocial contract (exit and voice are required for norms to bind), just as the FSC's certification standards formally apply only to companies that choose to participate in the scheme. Perhaps ISO 26000 sets a very compelling standard, and perhaps that standard would meet the criteria set by Donaldson and Dunfee's hypernorms. To be clear, we are in no way saying that by refusing to sign up for ISO 26000 a company can breach its standards with moral impunity under DAML. Rather, the bindingness of the relevant standard in such a case would not depend upon the input legitimacy of ISO 26000 (including the lack of participation of the target company in the deliberations that gave rise to ISO 26000). That brings us back to the hypernorm challenge.

Donaldson and Dunfee did not face this bindingness problem because they had a different conception of hypernorms in mind. For them, since hypernorms are universally binding by agreement of the hypothetical macrosocial contractors, hypernorms are supposed to bind everyone, everywhere by force of the thought experiment (1999: 27-28; 2003: 116-17; see Smith, 2001). It is this presumed feature of hypernorms that underwrites ISCT's claim to limit everyone's moral free space and, most relevant in our discussion, establishes hypernorms as second-order norms against which to test (everyone's) microsocial norms (i.e., lower order norms whose authenticity hinges on exit and voice). If Donaldson and Dunfee's hypernorms are fully replaced in the framework and substituted only with (historically contingent) 
justified hypernorms, who is bound by those justified hypernorms? And why? The solution we propose to this conundrum is simple and effective: recognize (in line with ISCT's account of authentic norms) the extra-strength bind that results from voluntary subscription to a hypernorm portfolio that spells out the commitments publicly for all to see (which is not to deny the existence or force in fact of unwritten yet deep-seated hypernorms). Accordingly, we settle upon the following statement of ISCT*: managing according to a master portfolio of justified hypernorms (universal in scope, arguably satisfying the input legitimacy condition) that set self-imposed and publicly announced bounds on local (microsocial) norms and business activity generally.

In the following two sections, we road-test ISCT* to examine its potential to fulfill each of the two functions of hypernorms within the ISCT framework: setting outer bounds (negative prohibition), and affirmatively sanctioning local norms and activity.

\section{ISCT* AND THE ENDURING POTENTIAL OF JUSTIFIED HYPERNORMS: OUTER BOUNDS}

The purpose of this section is to examine whether justified hypernorms can fulfill the outer bounds function in ISCT* (as just stated) in a manner that is defensible under DAML. We conclude that it can.

By its design, the ISCT* we have presented in this article shines as a screening device that negatively excludes microsocial norms and business practices of questionable legitimacy. ISCT is designed around this function, which makes ISCT* that much easier for managers to apply when their companies have expressly subscribed to applicable justified hypernorms that are spelled out. Justified hypernorms can be read off the page, with the plain professional obligation to do so once the company undertakes a voluntary public commitment to a portfolio of justified hypernorms (e.g., ISO 26000). There is no need for guesswork and intuitions about convergent traditions, religious norms, shared values, and the like. These company-level commitments, we now argue, can provide legitimate guidance to managers in the negativethrough the microsocial norms and business decisions that the company's "hypernorm portfolio" would reject, assuming a suitable hypernorm portfolio (see section 7).

To develop intuitions about the boundary-setting function of justified hypernorms, we take a real case from the financial services industry with alternative counterfactuals. According to a 2013 US Department of Labor order, Bank of America (BoA) "applied unfair and inconsistent selection criteria resulting in the rejection of qualified African American applicants for teller and entry-level clerical and administrative positions" (US Department of Labor, 2017). The inquiry into BoA's hiring practices went back twenty years to "a routine compliance review that revealed indications of systemic hiring discrimination affecting African-American job seekers at the Charlotte [North Carolina] facility" (US Department of Labor, 2017). Assume that the unfairness of the hiring practices was evidently racially discriminatory and, counterfactually, that BoA was, during the period in question, a signatory to the ISO 26000, which sets forth implementable guidelines in line with "the primacy of human rights [as] emphasized by the international community in the International 
Bill of Human Rights and core human rights instruments" (ISO 26000: §6.3.1.1). ${ }^{4}$ In this case, BoA would have been governed by an applicable justified hypernorm:

Section 6.3.3.1. To respect human rights, organizations have a responsibility to exercise due diligence to identify, prevent and address actual or potential human rights impacts resulting from their activities or the activities of those with which they have relationships.

Would it be permissible under its voluntary commitments for BoA to institute hiring practices (i.e., microsocial norms, see Donaldson \& Dunfee, 1999: 42) that are racially discriminatory in the manner of its Charlotte office practice? To figure this out, a manager at BoA would scan for justified hypernorms, and would find an applicable obligation in ISO 26000 (that her bank has signed up for). Its principles of human rights, nondiscrimination, and proactive due diligence flatly oppose that hiring practice. There is no way to square this practice of discrimination under ISCT*. BoA's having subscribed to ISO 26000 makes the following as true for ISCT* as for the ISCT that Donaldson and Dunfee were theorizing: "Even if the norm of racial discrimination is, or was in certain places and times, considered authentic in the South, it cannot be classified as a legitimate norm under ISCT since it is inconsistent with the hypernorm ensuring the fundamental right not to be discriminated against" (2003: 117).

This case illustrates the immense practicability of ISCT*. Managers at BoA receive quick and applied guidance as to what not to do (that does not require managers in a company to reach and act on shared understandings about core human values). No discourse is necessary. It is critical to our present argument to see that this prohibition involves no balancing test, and certainly no requirement of further discourse with stakeholders. There is no need to ask or to discuss the alternatives to engaging with the practice whose contemplation is jolting the high-voltage fence of the justified hypernorm in question. The present question about the moral legitimacy of ISCT* on a discursive account involves a company deciding to hold off on endorsing a business decision that is controversial on its face under express commitments that the company has formally underwritten publicly and without conflict with positive law. We see no basis to question the legitimacy of this application of ISO 26000 under DAML.

The net result is that BoA's (counterfactual) decision not to engage in racial discrimination would have reflected respect for BoA's express commitment to the fruits of the discursive process that gave rise to ISO 26000. This hypernorm portfolio tells BoA and its agents to cease, or better yet, not institute the practice in the first place. They don't need to engage in multi-stakeholder discourse to reach this conclusion. The discourse that is embedded in the arguably justified hypernorm provides a boundary that commands respect. The universal principle of nondiscrimination comes directly between BoA and the adoption of the hiring policy instituted in its Charlotte office. Taking guidance from justified hypernorms enhances rather than detracts from a company's moral legitimacy insomuch as managers are prompted to heed a commitment of their company not to breach set limits, where those limits are rooted in a global discourse giving rise to guidance in the form of universal principles. 
The same analysis applies to any conflict between justified hypernorms and microsocial norms or business decisions. In all such cases, the negative screening mechanism of justified hypernorms provides a boundary condition that rules out activity beyond set limits. For the foregoing reasons, we have argued that an ISCT* applied under a (suitable) portfolio of justified hypernorms provides a valuable and immensely practical "life jacket" that helps keep business inside the bounds of moral legitimacy that were established, in our example, through ISO 26000's multi-stakeholder discursive engagement.

Clearly, the utility and effectiveness of ISCT* depends on the quality of a company's hypernorm portfolio. We will explore the factors that inform a hypernorm portfolio's suitability in section 7 . Next, the task is to examine the other side of the biconditional role that hypernorms play in Donaldson and Dunfee's ISCT: Can justified hypernorms provide not only a life jacket to keep companies within moral minimums, but also a safe harbor that affirmatively endorses the moral legitimacy of microsocial norms and business practices?

\section{ISCT* AND THE ENDURING POTENTIAL OF JUSTIFIED HYPERNORMS: DISCURSIVE STARTING POINT RATHER THAN SAFE HARBOR}

In Donaldson and Dunfee's presentation of ISCT, the authenticity of a microsocial norm depends on procedural requirements, but its moral legitimacy comes from its compatibility with hypernorms. Can arguably justified hypernorms play an equivalent function in ISCT*? Assuming a suitable hypernorm portfolio, can managers adopt the posture of a moral safe harbor so long as they fall within its strictures? There are at two reasons why we argue ISCT* can provide nothing quite like the moral safe harbor intended under ISCT. Nevertheless, as we will show, the framework can play an important role to help ensure the moral legitimacy of a company under DAML.

The first reason why ISCT* cannot provide a moral safe harbor is that, unlike Donaldson and Dunfee's hypernorms, which seem to be inherently up to date and comprehensive, there is no guarantee that this would be the case with a portfolio of justified hypernorms. Even more fundamentally, the issue turns on the difference between the modalities of ISCT (static and property-like) and DAML (dynamic and processual) (see Table 1) (cf. Suddaby, Bitektine, \& Haack, 2017).

The difference between these modalities can be appreciated in the distinction between owning a home and renting the same home. The home-dweller with the property right can lean on a past-tense fact: transfer of title to the home-dweller. As we have indicated and will now demonstrate, managing ISCT* as if it yields a moral safe harbor is bound to fail DAML. ISCT*'s modality of legitimacy is not like owning but rather like renting a home in the sense that ongoing occupancy requires ongoing rental payments (see Suddaby et al., 2017). No rent, no home. The same, we argue, goes for justified hypernorms. The moment management shuts down the ongoing conversation about the limits of justified hypernorms, moral legitimacy under DAML is at peril. To the question of whether ISCT* can provide guidance with the requisite legitimacy, we answer in the negative, but that is if one seeks the property-like safe harbor afforded under Donaldson and Dunfee's ISCT. If the modality sought 
from ISCT* (see Table 1) is static and check-the-box, then yes, ISCT* necessarily fails under DAML. Fortunately, as we now demonstrate with an example, there is another way to apply ISCT* that helps companies successfully sustain their moral legitimacy in the discursive, processual sense demanded by DAML.

Reconsider the Bank of America example above; dial back the calendar one hundred years; and suppose, counterfactually, that the justified hypernorms on offer and subscribed to by BoA track the constitutional law then in place in the United States. The principle of nondiscrimination and the conception of human rights applicable under BoA's hypernorm portfolio is satisfied by "separate but equal" (Plessy v. Ferguson, 1896). Would there nevertheless be value to a company's being subscribed to a justified hypernorm about nondiscrimination that accommodates racism realized through separate but "equal" opportunities? The reality is that even the separate-but-equal norm has teeth: it rules out prima facie unequal treatment of racial groups, and that, we claim as per the previous section, retains enduring value. It is a good and defensible thing for a manager to step back and reconsider instituting a business policy that is racially discriminatory on its face. (The reality, unfortunately, is that companies readily find proxy categories with which to exhibit racial animosity [Mui, 2012].)

Now set the calendar back to 1954 when the Supreme Court rejected separatebut-equal as a conception of nondiscrimination. Suppose a decade goes by and the hypernorm portfolio BoA is subscribed to still treats separate-but-equal as a permissible form of discrimination. It's not to suggest that the Supreme Court of the United States is a leading moral authority, but that times change and with them the understanding of permissible boundaries. In defending the value of arguably justified hypernorms as outer bounds earlier, we did not attempt to argue that the limits being set by a company's chosen hypernorm portfolio are demanding enough to satisfy stakeholders as times change. The adequacy of the bounds set by a given hypernorm portfolio is always an open question. To attend to this potential gap, ISO 26000 and other MSIs build in an automatic consideration of updating norms, as technologies and social issues and standards shift (e.g., ISO, 2017; cf. ISO, 2010: §7).

So, in the present hypothetical case, imagine it is now 1964, and BoA maintains strict racial segregation as to restrooms, cafeterias, and with few exceptions, job categories. Can managers defend the moral legitimacy of their conduct just by virtue of falling within the line drawn by the relevant justified hypernorm? ISCT is meant to fulfill this function via hypernorms, and to be able to do so would be to enjoy the static, property-like modality of safe harbor. The BoA case makes it easy to see that managers cannot rest their laurels on justified hypernorms-"separate but equal" will not get far in present day public discourse. Justified hypernorms not only become stale, they are presumptively stale. It is in the openness to freshen them up with new discursive engagement that companies "pay the rent" and make the ongoing case for moral legitimacy under DAML. The only remedy for staleness is to confront affected parties to find out whether, say, separate but equal passes muster today (if it ever did). The consensus codified in a justified hypernorm may, as Scherer (2015) emphasizes, "turn out to be a false consensus. The validity of normative claims may be challenged by new evidence or by new actors entering the discourse" (2015: 509; see Donaldson \& Dunfee, 2003: 117). 
What we take from this limitation is not the need to throw out the baby with the bath water, i.e., renounce any discursively legitimate role at all for ISCT* outside the outer bounds function. So long as managers themselves adopt a dynamic modality, the enduring value of justified hypernorms goes further than the life jacket function. Capturing that value requires, as a premise, the proposition that even the justified hypernorms that result from a pristine Habermasian discourse are never more than arguably justified hypernorms. Justified hypernorms are provisional hypotheses, handy points of departure both for conduct and for framing forward-looking stakeholder discourse to tailor norms to local facts. This provisional quality does not impugn our case for the value of justified hypernorms in setting outer bounds. What we can see now is that justified hypernorms can support morally legitimate engagement insomuch as the company becomes positioned to engage stakeholders constructively — departing from the applicable justified hypernorm-to address the case at hand, whether that means updating the hypernorm, developing microsocial norms, or otherwise deliberating about action.

Now return to the case of the hypothetical BoA in the early 1960s. Suppose top management is making decisions about a major human resources reorganization and renovation of the facilities and that its proclivities would be to favor separate-but-equal arrangements if there is a good economic case to be made. The thought experiment requires imagining that top management brings the issue to multi-stakeholder engagement, for example, with the National Association for the Advancement of Colored People (NAACP) and other non-governmental organizations with concern for employees, trade unions and other labor representatives, local communities, and governments. Engaging in this discourse in good faith will speak to the question of fair treatment and discrimination in the workplace. And when kicking off this conversation, BoA's managers, if faithful to BoA's hypernorm portfolio, will depart from the premise of equality, even if also with the separate-but-equal principle glossing its meaning. This, first, establishes a moral minimum to the discursive negotiation. In addition, because the company subscribed to the justified hypernorm with definite provenance, managers can rehearse the arguments behind the status quo version of the norm (see Table 1).

By this point we can see that the enduring role for justified hypernorms-beyond the life-jacket function of setting outer bounds-is a reflection of the dynamic modality that defines DAML. This modality is process-based: moral legitimacy is a function of doing - not merely the opening bid written on paper, but requiring the willingness of the company to explain and listen, drawing support and confidence from the existing hypernorm portfolio (see Table 1).

\section{DEVELOPING A SUITABLE HYPERNORM PORTFOLIO}

Unlike Donaldson and Dunfee's ISCT, ISCT* requires managers who wish to receive the benefits of its guidance to pick and choose which portfolios of arguably justified hypernorms bind them and to follow. The enduring potential of arguably justified hypernorms within ISCT* (the outer bounds function, section 5, and as a discursive starting point, section 6) depends directly on the quality of a company's 
hypernorm portfolio. Up to this point, we have stipulated a "suitable" hypernorm portfolio, but what makes a hypernorm portfolio suitable? And how should a company's managers develop and update theirs? In this article, we can only sketch the major considerations - the limited selection, comprehensiveness, and freshnesswith a concluding remark about the demandingness of justified hypernorms.

The first point is that while there might be plenty of discursively justified norms like the FSC principles (see Mena \& Palazzo, 2012), there will only be a limited selection of portfolios that will arguably satisfy the universal scope condition (with input legitimacy) and thus qualify as potential justified hypernorms (see Gradert \& Engel, 2015). Justifying hypernorms demands substantial efforts from many parties in order to organize multi-stakeholder discourses that fulfill the input legitimacy conditions. The paucity of choice suggests companies may need to supplement discursively justified hypernorms with hypernorms otherwise developed. As Donaldson (2017: 138) explains:

For example, corporations memorialize limits on what's allowed when pursuing profit using credo statements that reflect first-order moral (hypernorm) status. Such statements list hard-to-disagree-with ideals/hypernorms such as "trust," "respect" and "integrity." Moreover, groups of economic actors generate workable precepts that they strive to uphold, e.g., the Caux Round Table Principles, the Ruggie Principles, the United Nations Global Compact, ISO 26000, mission statements, and codes of ethics.

Given the limited choice set confronting managers, comprehensiveness becomes a major factor determining the suitability of a company's hypernorm portfolio. The comprehensiveness of a hypernorm portfolio influences the range of contexts and situations in which the company's managers will find a life jacket to save them. We do not need to give a rigorous definition of the concept of comprehensiveness to observe that, in practical terms, companies may choose to develop a master portfolio that combines, say, ISO 26000 with some other plausible candidate to provide managers even greater coverage than that afforded by ISO 26000's already thick portfolio. On the other hand, hypernorm portfolios may reference common elements, such as the United Nations Declaration of Human Rights, which ISO 26000 and several other hypernorm portfolios (not all arguably justified) each incorporate by reference (Gradert \& Engel, 2015: 7). Whether a company's (master) hypernorm portfolio is comprehensive enough - in absolute terms or given available options-is a question for a company's managers and its stakeholders to figure out.

The freshness of justified hypernorms also matters considerably to the suitability of a hypernorm portfolio, as reflected in the "separate but equal" hypothetical case above. Global business is dynamic and normative adaptation a sine qua non to survival. This recommends the approach adopted by ISO, which is to build adaptation into the regular protocols of the MSI (even though the group recently confirmed a vote not to update the standards before 2020) (ISO, 2017). In the absence of institutionalized revisions, companies may need to proactively become norm-makers with calls to revise justified hypernorms when substantive new issues or technologies arise that create pressing regulatory voids (de los Reyes et al., 2017: 149-52). The frequency of and precise form to be taken by recurrent norm-making are both important issues but are beyond the scope of this article. 
To be clear, we have not argued in this section that moral legitimacy under DAML categorically requires companies to subscribe to justified hypernorms. Rather, the principle is roughly that the weaker the coverage provided by a company's hypernorm portfolio-less comprehensive and more stale-the more explaining (and learning) its managers must be prepared to do. Put differently, the company that is morally compelled to subscribe to a hypernorm portfolio finds itself in that position because it has no justification for not doing so, in light of all the reasons for doing so. Managing a large company, especially a global corporation operating across multiple jurisdictions and cultures, is challenging enough. To willfully eschew the clarity of purpose that managers draw from publicly stated commitments may, depending on circumstances and history, seem irresponsible and difficult to defend to stakeholders who could suffer the negative consequence.

The categories of comprehensiveness and freshness represent two different ways to call into question the demandingness of a hypernorm portfolio. To inquire whether a company's hypernorm portfolio is fresh enough (whether it has been updated to address recent reconceptualizations of core human values) can be just a different way of asking about comprehensiveness (whether the hypernorm portfolio speaks to the range of relevant issues facing a company). Regardless, as these are two sides of the same coin, the force of the question is identical: Is the company's hypernorm portfolio demanding enough? Consider the case of artificial intelligence (AI). None of the ISO 26000 guidelines address, for example, the emerging ethical issues arising from human resource use of AI. It is, however, possible that soon AI will evolve to the point where society grapples with the challenges to human rights resulting from AI. Absent updating, the ISO 26000 will fail to provide managers any practical guidance, and this limitation can be characterized as a failure of comprehensiveness and/or freshness. Either way, the concern would be that ISO 26000 is not demanding enough.

The belt on the suspenders of even undemanding hypernorm portfolios under ISCT* is openness to playing the part of "a transparent, accountable, and collaborative actor within its societal or stakeholder context" (Scherer \& Palazzo, 2007: 1114). The same belt of discursive openness is also needed to cover for the lacuna left by an insufficiently comprehensive and fresh hypernorm portfolio. In sum, the basic shift presented by ISCT* is not to take moral free space for granted. Donaldson and Dunfee say that "hypernorms are recognized by macrosocial contractors as key limits on moral free space" (1999: 49). Managers applying ISCT* expect to find limits beyond their company's hypernorm portfolio, and discursive engagement is the mode of discovery. Whereas ISCT provides managers (who have a sense of hypernorms and awareness of the company's microsocial commitments) confidence in the moral legitimacy of corporate strategy, managing under ISCT* is much more like feeling one's way in the dark. A company's hypernorm portfolio and microsocial commitments command respect, but in the manner of a life jacket, not a moral safe harbor. ISCT* requires managers to remain generally open for further discourse, whether to put a finer, more contextualized point on an arguably justified hypernorm, or to extend and sharpen microsocial norms. 


\section{CONCLUSION}

Responding to the hypernorm challenge and taking the path suggested by Scherer (2015) and Donaldson (2017), we began our reconstructive program of ISCT from an earlier proposal (Gilbert \& Behnam, 2009) to bolster ISCT with hypernorms justified through multi-stakeholder discourse. We critically assessed and modified this proposal, in the first instance by delimiting the category with the requirement of universal scope (so as to preserve ISCT's hierarchy of norms and the requisite input legitimacy). We then noted the need to focus on the case of companies that have subscribed to a hypernorm portfolio (so as to crystallize the bindingness for managers through a quasi-contractual commitment).

Managers at these companies can gather highly practical insights from ISCT*; in particular, these arguably justified hypernorms provide outer bounds, or moral minimums, that limit business activity in a morally defensible way under DAML. They are like a life jacket powerful enough to counsel against the dictates of microsocial norms — or business advantage — that managers would otherwise be inclined to follow. The logic of Donaldson and Dunfee's ISCT would suggest that managers could remain within a moral safe harbor (affirmative endorsement of the permissibility of conduct) so long as the bounds of hypernorms have been respected. However, DAML relies on a dynamic modality, wherein moral legitimacy remains always in question and only the open willingness to engage in multi-stakeholder discourse can sustain ongoing legitimacy. This is why we analogized to the case of renting a home: if a company shuts the door to multi-stakeholder engagement, moral legitimacy vanishes, just like being subject to eviction when rent is not paid.

And the "rent" does frequently come due. Scherer (2015) quotes Habermas (2003: 44) for the proposition that "new issues arise, new norms must be developed and justified in light of new challenges in history" (2015: 507).

Any consensus concerning values or norms that is reached under ideal or almost ideal conditions is assumed to be valid only among those who have taken part in the argumentation process. However, it may turn out to be a false consensus. The validity of normative claims may be challenged by new evidence or by new actors entering the discourse (Scherer, 2015: 509).

Nevertheless, rent is not due every day. Donaldson (2017) reminds us that "it is important that their conversations pause from time to time" (2017: 138) and there are many "paused conversations" to choose from in binding a company to an express moral commitment:

In the economic sphere, Corporation A may subscribe to and adopt the principles of the United Nations Global Compact, including the United Nations Declaration of Human Rights (1948) and the principles promulgated by the ILO; Corporation B may subscribe to the Caux Round Table Principles for Responsible Business (2009); yet another may utilize Donaldson's list of ten Fundamental International Rights (1989: 81) (Donaldson, 2017: 139). 
Donaldson's (2017) view overlaps substantially with Scherer's: "Better and worse lists are drawn up; hence the need for ongoing, well-formed discussion" (2015: 139).

One might want to confront metaethical questions we expressly set aside—-such as whether the universalization of norms, if possible, is actually a necessary or desirable endeavor (for an overview of this question from a postmodernist and analytical perspective, see Scherer, 2015). Where the focus is on large, and especially transnational corporations, justified hypernorms, we have argued, play an indispensable practical role, erecting consistent and express moral minimums that can provide vital guidelines for practice-as outer bounds and discursive starting points. With all the legitimacy that issues from their roots, justified hypernorms lead companies away from many of the problematic and yet widespread business practices and microsocial norms that remain prevalent today. As such, justified hypernorms can provide an excellent normative litmus test that yields quick and accessible guidance to managers about outer bounds of conduct and premises for open stakeholder engagement. With companies that have subscribed to a suitable hypernorm portfolio - reasonably comprehensive and fresh enough-ISCT* presents an applied framework full of potential to facilitate management according to the aspirations of DAML.

But none of this is true if ISCT* is conceptualized statically, as a way to safeguard and "own" moral legitimacy (Suddaby et al., 2017). The legitimacy of justified hypernorms under DAML is likely to have lost freshness immediately after the parties who initially gave effect to the justified hypernorms left the discursive arena (as when a new car loses value the moment it leaves the sales lot). The "staleness" of a justified hypernorm - to be clear-is also a feature and not merely a liability. It is the very dryness of the ink that materializes the justified hypernorm and makes it tractable within an organization, even a global hierarchy, for calibration and ready application from its home in a hypernorm portfolio. The specificity and fixed nature of the justified hypernorm makes it the subject of imitation, whether because managers are copying competitors or have been influenced to agree with the ideas. Either way, the grand virtue in a market economy of dissemination of a given portfolio of justified hypernorms is cancelling the competitive disadvantage of adhering to the norm (Buchanan, 1996). The dry ink of past commitment steers business decisions where discussion is costly and unnecessary. Moreover, these (temporarily) frozen commitments inform the discursive agenda when the time comes to pay the rent.

How often managers need to refresh the discourse that initially justified the hypernorms is a question we have left aside. On a day-to-day basis, a company's discursive focus will naturally tend to microsocial engagements with fewer stakeholders and more localized agendas. However, depending on applicable microsocial norms, it may well be a company's justified hypernorms that provide the leading edge of a discursive engagement, even in localized discourses. While ISCT* represents "a kind of Everyman's conceptual scheme" (Andrews, 1969: 162) that helps manage a company's discursive agenda, it only does so at a high level, and a promising direction for further research is to elucidate how managers can and should interpret and translate the external environment into effective "stakeholder learning dialogues" (Donaldson \& Dunfee, 2003: 119). Whereas the business ethicists who have begun to address this project have emphasized the question of when managers 
need to provoke norm-making (Baumann-Pauly, 2013; Donaldson \& Schoemaker, 2013; Scherer, Palazzo, \& Seidl, 2013; see de los Reyes et al., 2017: 155-57), much more work is required to provide managers tractable roadmaps for how to pursue norm-making activities (see de los Reyes et al., 2017: 157-59). ${ }^{5}$

\section{ACKNOWLEDGEMENTS}

The first two authors contributed equally. We would like to thank the three anonymous reviewers and our action editor for their critical feedback and valuable suggestions. Their work helped us to significantly improve our article. Craig Smith gratefully acknowledges Dreyfus Sons \& Co. Ltd., Banquiers for its financial support of his contributions to this project.

\section{NOTES}

1. Donaldson and Dunfee (2009) also account for procedural and structural hypernorms (2009: 51-53). For convenience and consistency with other authors (see Scherer \& Palazzo, 2007), we reference "substantive hypernorms" as hypernorms for short, except below where specifically referencing Gilbert and Behnam's "development of a procedural framework to justify hypernorms" (2009: 219).

2. The exact meaning of "must be able to participate" is a question we note and set aside.

3. We use the word "arguably" to modify "justified hypernorm" for a specific and theoretically critical reason. At the threshold, we recognize that empirical questions can always be asked about satisfaction of the input legitimacy condition, especially when it comes to hypernorms, like ISO 26000, as opposed to industrybased norms (because of the requisite vastness of scale and scope). To say that hypernorms are arguably justified is to say there is a decent empirical case to be made for satisfaction of the input legitimacy condition. Moreover, "arguably" captures the best-case scenario for a discursively-derived hypernorm: that it does make a good case. And it similarly captures the worst case: that upon challenge the "arguably" justified hypernorm does not hold up to argument, just like a legal claim may fail in court. The putative hypernorm can fail the argument as a matter of its processual roots, meaning that it becomes untenable to claim that the input legitimacy condition was satisfied. And, as we will discuss in section 6 , it can fail substantively, meaning that it becomes untenable to defend the moral legitimacy of the line drawn by the putative hypernorm.

4. In effect, ISO 26000 embeds an earlier hypernorm portfolio (the International Bill of Human Rights), whose arguable justification-likely less plausible_involved different actors and processes.

5. Scherer et al. (2013: 263-64) suggest that in order to maintain their legitimacy, companies should engage in moral discourse when they perceive a mismatch between the corporation's status quo and societal expectations if attempts at strategic persuasion to adjust these expectations and/or isomorphic adaptation strategies have failed. Donaldson and Schoemaker (2013) identify a series of risk factors (innovation is rapid, regulators are weak, too much is hidden, experts are few, "hush" prevails, and critics are ignored) that can signal to executives that it is time to engage in norm-making for the sake of industry legitimacy and health. While both approaches provide promising starting points, the question of when and why companies should initially engage in norm-making processes or refresh microsocial norms (such as the FSC) and arguably justified hypernorms (such as the ISO 26000) remains a pressing topic for further research (de los Reyes et al., 2017).

\section{REFERENCES}

Andrews, K. R. 1969. The progress of professional education for business. Theological Education, 5: 144-66.

Baumann-Pauly, D. 2013. Managing corporate legitimacy: A toolkit. London: Routledge.

Bicchieri, C. 2016. Norms in the wild: How to diagnose, measure, and change social norms. New York: Oxford University Press.

Boatright, J. R. 2000. Globalization and the ethics of business. Business Ethics Quarterly, 10(1): $1-6$. 
Brenkert, G. G. 2009. ISCT, hypernorms, and business: A reinterpretation. Journal of Business Ethics, 4(88): 645-58.

Bucar, B., Glas, M., \& Hisrich, R. D. 2003. Ethics and entrepreneurs: An international comparative study. Journal of Business Venturing, 18(2): 261-81.

Buchanan, A. 1996. Perfecting imperfect duties: Collective action to create moral obligations. Business Ethics Quarterly, 6(1): 27-42.

Castka, P., \& Balzarova, M. A. 2008. Adoption of social responsibility through the expansion of existing management systems. Industrial Management \& Data Systems, 108: 297-309.

Conger, S., \& Loch, K. D. 2000. Invitation to a public debate on ethical computer use. ACM SIGMIS Database, 32(1): 58-69.

Donaldson, T. 1996. Values in tension: Ethics away from home. Harvard Business Review, 74(5): 48-62.

de los Reyes, G., Scholz, M., \& Smith, N. C. 2017. Beyond the "win-win": Creating shared value requires ethical frameworks. California Management Review, 59(2): 142-67.

Donaldson, T., \& Dunfee, T. W. 1994. Toward a unified conception of business ethics: Integrative social contracts theory. Academy of Management Review, 19(2): 252-84.

Donaldson, T., \& Dunfee, T. W. 1999. Ties that bind: A social contracts approach to business ethics. Boston, MA: Harvard Business School Press.

Donaldson, T., \& Dunfee, T. W. 2002. Ties that bind in business ethics: Social contracts and why they matter. Journal of Banking \& Finance, 26(9): 1853-65.

Donaldson, T., \& Dunfee, T. W. 2003. Social contracts, sic et non. In P. Heugens, J. van Oosterhout, \& J. Vromen (Eds.), The social institutions of capitalism. Evolution and design of social contracts: 109-126. Cheltenham, United Kingdom: Edward Elgar Pub.

Donaldson, T., \& Schoemaker, P. J. H. 2013. Self-inflicted industry wounds: Early warning signals and pelican gambits. California Management Review, 55(2): 24-45.

Donaldson, T. 2017. Donaldsonian themes: A commentary. Business Ethics Quarterly, 27(1): $125-42$.

Douglas, M. 2000. Integrative social contracts theory: Hype over hypernorms. Journal of Business Ethics, 26(2): 101-10.

Dunfee, T. W. 2006. A critical perspective of integrative social contracts theory: Recurring criticisms and next generation research topics. Journal of Business Ethics, 68(3): 303-28.

Dunfee, T. W., Smith, N. C., \& Ross Jr., William T. 1999. Social contracts and marketing ethics. Journal of Marketing, 63(3): 14-32.

Dworkin, R. 1973. The original position. The University of Chicago Law Review, 40(3): 500-33.

Forest Stewardship Council (FSC). 2014. FSC international standard: Principles and criteria for forest stewardship. Bonn, DE (FSC-STD-01-001 V5-1 EN).

Gilbert, D. U., \& Behnam, M. 2009. Advancing integrative social contracts theory: A Habermasian perspective. Journal of Business Ethics, 89(2): 215-34.

Gradert, M., \& Engel, P. 2015. A comparison of 4 international guidelines for CSR. Copenhagen: Danish Business Authority.

Habermas, J. 1984. The theory of communicative action. Volume I: Reason and the rationalization of society. Boston, MA: Beacon Press.

Habermas, J. 1985. The theory of communicative action. Volume II: Lifeworld and system: A critique of functionalist reason. Boston, MA: Beacon Press.

Habermas, J. 1990. Moral consciousness and communicative action. Cambridge, MA: MIT Press.

Habermas, J. 1993. Justification and application: Remarks on discourse ethics. Cambridge, MA: MIT Press. 
Habermas, J. 1996. Between facts and norms: Contributions to a discourse theory of law and democracy. Cambridge, MA: MIT Press.

Habermas, J. 1998. The inclusion of the other: Studies in political theory. Cambridge, MA: MIT Press.

Habermas, J. 2001. Constitutional democracy: A paradoxical union of contradictory principles? Political Theory, 29(6): 766-81.

Habermas, J. 2003. Introduction: Realism after the linguistic turn. In J. Habermas, Truth and justification: 1-49. Cambridge, MA: Polity Press.

Habermas, J. 2006. Political communication in media society: Does democracy still enjoy an epistemic dimension? The impact of normative theory on empirical research. Communication theory, 16(4): 411-26.

Hahn, R. 2012a. Inclusive business, human rights and the dignity of the poor: A glance beyond economic impacts of adapted business models. Business Ethics: A European Review, 21(1): 47-63.

Hahn, R. 2012b. Standardizing social responsibility? New perspectives on guidance documents and management system standards for sustainable development. IEEE Transactions on Engineering Management, 59(4): 717-27.

Hahn, R., \& Weidtmann, C. 2016. Transnational governance, deliberative democracy, and the legitimacy of ISO 26000: Analyzing the case of a global multistakeholder process. Business \& Society, 55(1): 90-129.

Hartman, L. P., Shaw, B., \& Stevenson, R. 2003. Exploring the ethics and economics of global labor standards: A challenge to integrated social contract theory. Business Ethics Quarterly, 13(2): 193-220.

Hursthouse, R. 1995. Fallacies and moral dilemmas. Argumentation, 9(4): 617-32.

Hussain, W., \& Moriarty, J. 2016. Accountable to whom? Rethinking the role of corporations in political CSR. Journal of Business Ethics, 1-16.

International Organization for Standardization (ISO). 2010. ISO 26000:2010 Guidance on Social Responsibility. https://www.iso.org/standard/42546.html.

International Organization for Standardization (ISO). 2017. ISO TMB: ISO 26000 is confirmed. December 11, 2017. http://iso26000.info/iso/iso-standards/iso-26000/ iso-tmb-iso-26000-confirmed.

Logsdon, J. M., \& Wood, D. J. 2002. Business citizenship: From domestic to global level of analysis. Business Ethics Quarterly, 12(2): 155-87.

Mayer, D., \& Cava, A. 1995. Social contract theory and gender discrimination: Some reflections on the Donaldson/Dunfee model. Business Ethics Quarterly, 5(2): 257-70.

McCarthy, D. J., \& Puffer, S. M. 2008. Interpreting the ethicality of corporate governance decisions in Russia: Utilizing integrative social contracts theory to evaluate the relevance of agency theory norms. Academy of Management Review, 33(1): 11-31.

Mena, S., \& Palazzo, G. 2012. Input and output legitimacy of multi-stakeholder initiatives. Business Ethics Quarterly, 22(3): 527-56.

Mui, Y. Q. 2012. Ex-loan officer claims Wells Fargo targeted black communities for shoddy loans. The Washington Post, June 12, 2012. https://www.washingtonpost. com/business/economy/former-wells-fargo-loan-officer-testifies-in-baltimoremortgage-lawsuit/2012/06/12/gJQA6EGtXV_story.html.

Palazzo, G., \& Scherer, A. G. 2006. Corporate legitimacy as deliberation: A communicative framework. Journal of Business Ethics, 66(1): 71-88.

Phillips, R. A., \& Johnson-Cramer, M. E. 2006. Ties that unwind: Dynamism in integrative social contracts theory. Journal of Business Ethics, 68(3): 283-302. 
Plessy v. Ferguson. 1896. United States Reports, 163: 537-64.

Reisel, W. D., \& Sama, L. M. 2004. Applying ISCT when norms are incompatible: The case of access to life-saving medicines in South Africa. Paper presented at the conference: Contractarian Approaches to Business Ethics: Evolution of Integrative Social Contract Theory, Philadelphia, PA.

Scherer, A. G. 2015. Can hypernorms be justified? Insights from a discourse-ethical perspective. Business Ethics Quarterly, 25(4): 489-516.

Scherer, A. G., \& Palazzo, G. 2007. Toward a political conception of corporate responsibility: Business and society seen from a Habermasian perspective. Academy of Management Review, 32(4): 1096-120.

Scherer, A. G., \& Palazzo, G. 2008. Globalization and corporate social responsibility. In A. Crane, A. McWilliams, D. Matten, J. Moon \& D. S. Siegel (Eds.), The Oxford handbook of corporate social responsibility: 413-31. Oxford, United Kingdom: Oxford University Press.

Scherer, A. G., \& Palazzo, G. 2011. The new political role of business in a globalized world: A review of a new perspective on CSR and its implications for the firm, governance, and democracy. Journal of Management Studies, 48(4): 899-931.

Scherer, A. G., Palazzo, G., \& Baumann, D. 2006. Global rules and private actors: Toward a new role of the transnational corporation in global governance. Business Ethics Quarterly, 16(4): 505-32.

Scherer, A. G., Palazzo, G., \& Matten, D. 2014. The business firm as a political actor: A new theory of the firm for a globalized world. Business \& Society, 53(2): 143-56.

Scherer, A. G., Palazzo, G., \& Seidl, D. 2013. Managing legitimacy in complex and heterogeneous environments: Sustainable development in a globalized world. Journal of Management Studies, 50(2): 259-84.

Scherer, A. G., Rasche, A., Palazzo, G., \& Spicer, A. 2016. Managing for political corporate social responsibility: New challenges and directions for PCSR 2.0. Journal of Management Studies, 53(3): 273-98.

Shaw, B. 2000. Book review dialogue: Ties that bind. American Business Law Journal, 37(3): 563-78.

Smith, N. C. 2001. Social marketing and social contracts: Applying integrative social contracts theory to ethical issues in social marketing. In A. R. Andreason (Ed.), Ethics in social marketing: 125-59. Washington, D.C.: Georgetown University Press.

Stark, A. 2015. Inverting Donaldson's framework: A managerial approach to international conflicts of cultural and economic norms. Business Ethics Quarterly, 25(4): 535-58.

Suddaby, R., Bitektine, A., \& Haack, P. 2017. Legitimacy. Academy of Management Annals, 11(1): 451-78.

United States Department of Labor. 2013 Judge orders Bank of America to pay almost \$ 2.2 million for racial discrimination against more than 1,100 African-American job seekers. Sept. 23, 2013. https://www.dol.gov/newsroom/releases/ofccp/ofccp20131967.

van Oosterhout, J. H., Heugens, P. P. M., \& Kaptein, M. 2006. The internal morality of contracting: Advancing the contractualist endeavor in business ethics. Academy of Management Review, 31(3): 521-39.

van Oosterhout, J. H., \& Heugens, P. P. M. 2009. Extant social contracts in global business regulation: Outline of a research agenda. Journal of Business Ethics, 88: 729-40.

Windsor, D. 2016. Dynamics for integrative social contracts theory: norm evolution and individual mobility. Journal of Business Ethics, 1-13. 